\title{
Hemorrhoids, CTCAE 5.0
}

National Cancer Institute

\section{Source}

National Cancer Institute. Hemorrhoids, CT CAE 5.0. NCI Thesaurus. Code C146738.

A disorder characterized by the presence of dilated veins in the rectum and surrounding area. 